\title{
PENGARUH REKRUTMEN DAN KOMPENSASI TERHADAP KINERJA KARYAWAN DENGAN PENGAWASAN KERJA SEBAGAI VARIABEL MODERATING PADA PT. TITIAN ABADI LESTARI
}

\author{
Ari Soeti Yani dan Rinaldo \\ Universitas 17 Agustus 1945 Jakarta \\ arisoetiyani@yahoo.co.id dan Rinaldo.bachtiar90@gmail.com
}

\begin{abstract}
Abstrak. Penelitian ini adalah penelitian tentang "Pengaruh rekrutmen dan kompensasi terhadap kinerja karyawan dengan pengawasan kerja sebagai variabel moderating pada PT Titian Abadi Lestari". Variabel dependen dalam penelitian ini adalah kinerja karyawan. Variabel independennya adalah rekrutmen dan kompensasi. Serta varibel moderating dalam penelitian ini yaitu pengawasan kerja. Populasi dan sampel dalam penelitian ini adalah seluruh karyawan atau sebanyak 70 orang. Metode analisis yang digunakan dalam penelitian ini adalah uji kelayakan data, uji hipotesis dan uji variabel moderasi. Hasil penelitian uji kelayakan data membuktikan bahwa kuesioner valid dan reliabel. Sedangkan uji hipotesis secara parsial dan simultan membuktikan bahwa rekrutmen dan kompensasi secara bersama-sama berpengaruh signifikan terhadap kinerja karyawan. Hasil uji variabel moderasi membuktikan bahwa pengawasan kerja merupakan pure moderating dikarenakan hasil pengaruh $\mathrm{Z}$ terhadap $\mathrm{Y}$ pada output pertama dan pengaruh interaksi $\mathrm{Z} * \mathrm{X}_{1}$ pada output kedua, salah satunya signifikan. Sehingga pengawasan kerja memoderasi pengaruh rekrutmen dan kompensasi terhadap kinerja karyawan.
\end{abstract}

Kata Kunci : Rekrutmen, Kompensasi, Kinerja Pegawai, Regresi Linier Berganda, PT Abadi Lestari Titian

Abstract. This research about "Effect of Recruitment and Compensation against Employee Performance with Monitoring of Work as Moderating Variables at PT. Titian Abadi Lestari ". The dependent variable in this research is the employee's performance. Independent variable is the recruitment and compensation. As well moderating variables in this research is monitoring of work. Population and sample in this research is all employees or as many as 70 people. The analysis method used in this research is to test the feasibility of the data, test hypotheses and test moderating variable. Test result of Feasibility data proves the questionnaire is valid and reliable. While testing the hypothesis partially and simultaneously prove that the recruitment and compensation jointly and significant positive effect on employee performance. The test results proved that the moderating variable the monitoring of work is pure moderating because of the effect results $Z$ to $Y$ on the first output and the effect of the interaction $Z * X 1$ on the second output, one of them is significant. So monitoring of work affect recruitment and compensation moderating on employee performance.

Keywords: Recruitment; Compensation; Employee Performance, multiple linear regression, PT Abadi Lestari Titian

Berdasarkan fenomena yang ada kinerja masih menjadi permasalahan paling penting bagi perusahaan dalam memajukan usahanya. Dapat dilihat dari data tahun 2012-2014 PT. Titian Abadi Lestari mengalami penurunan kinerja. Hal ini dapat digambarkan dari penurunan kehadiran karyawan, kecakapan dan ketelitian dalam penyelesaian tugas serta kurangnya kerja sama antar tim kerja. Menurunnya kinerja dapat disebabkan dari kurangnya motivasi, job description yang tidak terarah, atau bahkan menempatkan seseorang tidak sesuai dengan kompetensi sehingga tidak bekerja dengan optimal. Namun dalam hal ini kinerja menurun dipengaruhi oleh proses rekrutmen yang tidak sesuai dengan prosedur perekrutan. Selain itu kompensasi juga menjadi salah satu faktor yang mempengaruhi kinerja. Serta faktor lain seperti pengawasan kerja yang 
baik dilakukan oleh atasan secara langsung mampu mempegaruhi kinerja karyawan.

Berdasarkan hal ini, penulis termotivasi untuk mengambil judul: "Pengaruh Rekrutmen dan Kompensasi Terhadap Kinerja Karyawan dengan Pengawasan Kerja Sebagai Variabel Moderating pada PT Titian Abadi Lestari. Adapun perumusan masalah dalam penelitian ini, antara lain: Apakah rekrutmen berpengaruh terhadap kinerja karyawan pada PT Titian Abadi Lestari, Apakah kompensasi berpengaruh terhadap kinerja karyawan pada PT Titian Abadi Lestari, Apakah rekrutmen dan kompensasi secara bersama-sama berpengaruh terhadap kinerja karyawan PT Titian Abadi Lestari, Apakah moderasi pengawasan kerja mampu memperkuat pengaruh rekrutmen terhadap kinerja karyawan PT Titian Abadi Lestari, Apakah moderasi pengawasan kerja mampu memperkuat pengaruh kompensasi terhadap kinerja karyawan PT Titian Abadi Lestari. Tujuan penelitian ini dimaksudkan untuk mengetahui apakah rekrutmen berpengaruh terhadap kinerja karyawan pada PT Titian Abadi Lestari, Untuk mengetahui apakah kompensasi beerpengaruh terhadap kinerja karyawan pada PT Titian Abadi Lestari, Untuk mengetahui apakah rekrutmen dan kompensasi secara bersama-sama berpengaruh terhadap kinerja karyawan PT Titian Abadi Lestari, Untuk mengetahui apakah pengawasan kerja sebagai variabel moderasi mampu memperkuat pengaruh rekrutmen terhadap kinerja karyawan PT Titian Abadi Lestari, Untuk mengetahui apakah pengawasan kerja sebagai variabel moderasi mampu memperkuat pengaruh kompensasi terhadap kinerja karyawan PT Titian Abadi Lestari.

Ada beberapa bahan acuan penelitian terdahulu yang menjadi bahan masukan bagi penulis diantaranya penelitian Hidayat (2012) yang menyatakan bahwa rekrutmen berpengaruh terhadap kinerja hampir 60\%, sedangkan hasil penelitian Ernawati (2013) menyatakan bahwa kompensasi berpengaruh signifikan terhadap kinerja sebesar $56 \%$. Ada pula penelitian Suseno (2013) yang menyatakan bahwa pengawasan mempunyai pengaruh terhadap kinerja pegawai.

\section{KAJIAN LITERATUR}

\section{Kinerja Karyawan.}

Menurut Mangkunegara (2000:67) kinerja ialah hasil kerja secara kualitas dan kuantitas yang dicapai oleh karyawan dalam melakukan tugasnya sesuai dengan tanggung jawab yang diberikan kepadanya. Menurut Mitchell (dalam Sedarmayanti, 2001: 51) kinerja meliputi beberapa aspek yaitu: 1) Quality of work; 2) Promptness; 3) Initiative; 4) Capability; 5) Communication.

\section{Rekrutmen.}

Menurut Mathis (2006: 112) rekrutmen adalah penarikan (rekrutmen) pegawai merupakan suatu proses/tindakan yang dilakukan organisasi dalam mendapatkan tambahan pegawai melalui beberapa tahapan, meliputi identifikasi dan evaluasi sumbersumber penarikan tenaga kerja, menentukan kebutuhan tenaga kerja, proses seleksi, penempatan, dan orientasi tenaga kerja. Sedangkan menurut Hasibuan (2009:40) rekrutmen ialah usaha mencari dan mempengaruhi tenaga kerja agar melamar lowongan pekerjaan dalam suatu perusahaan. Berdasarkan uraian di atas, maka ditetapkan hipotesis pertama, yaitu: $\mathrm{H}_{1}$ : Rekrutmen berpengaruh terhadap kinerja karyawan.

\section{Kompensasi.}

Menurut Hasibuan (2006: 118) kompensasi yaitu semua pendapatan yang berbentuk uang, barang langsung ataupun tidak langsung yang diterima karyawan sebagai imbalan atas jasa yang diberikan pada perusahaan. Sedangkan menurut Handoko (2003:155) kompensasi ialah segala sesuatu yang diterima karyawan sebagai balas jasa untuk kerja mereka yang berupa upah/gaji pokok yang pembayarannya diterima karyawan secara bulanan, mingguan ataupun setiap jam sebagai hasil dari pekerjaan mereka. Berdasarkan uraian diatas, maka ditetapkan hipotesis kedua yaitu: $\mathrm{H}_{2}$ : Kompensasi berpengaruh terhadap kinerja karyawan. 
Ari Soeti Yani dan Rinaldo, Pengaruh Rekrutmen Dan Kompensasi Terhadap Kinerja Karyawan...

\section{Rekrutmen, Kompensasi dan Kinerja Karyawan.}

Keberhasilan perusahaan tercermin dari kinerja karyawan yang optimal. Sehingga dalam organisasi, rekrutmen menjadi proses awal yang penting dalam menentukan baik tidaknya pelamar yang melamar pada organisasi tersebut. Kompensasi juga merupakan salah satu faktor yang mempengaruhi kinerja karyawan. Pemberian kompensasi akan membuat karyawan lebih termotivasi. Jika kompensasi yang diberikan oleh perusahaan sesuai dengan apa yang diharapkan dan sesuai dengan apa yang dikerjakan. Berdasarkan uraian di atas, maka ditetapkan hipotesis ketiga yaitu: $\mathrm{H}_{3}$ : Rekrutmen dan kompensasi secara bersamasama berpengaruh terhadap kinerja karyawan.

\section{Moderasi Pengawasan Kerja Atas Rekrutmen Terhadap Kinerja Karyawan.}

Menurut Harahap (2001:10), pengawasan meliputi memeriksa apakah semua berjalan sesuai dengan rencana yang ditetapkan, perintah yang dikeluarkan, prinsip yang dianut dan untuk mengetahui kelemahan dan kesalahan agar dapat dihindari kejadiannya dikemudian hari. Berdasarkan uraian diatas, maka ditetapkan hipotesis keempat yaitu: $\mathrm{H}_{4}$ : Pengawasan kerja mampu memperkuat secara signifikan pengaruh rekrutmen terhadap kinerja karyawan.

\section{Moderasi Pengawasan Kerja Atas Kompensasi Terhadap Kinerja Karyawan.}

Menurut Dale (dalam Winardi, 2000: 224) pengawasan tidak hanya melihat sesuatu dengan seksama dan melaporkan hasil kegiatan mengawasi, tetapi juga mengandung arti memperbaiki dan meluruskan. Sehingga mencapai tujuan yang sesuai dengan apa yang direncanakan. Berdasarkan uraian diatas, maka ditetapkan hipotesis kelima yaitu: $\mathrm{H}_{5}$ : Pengawasan kerja mampu memperkuat secara signifikan pengaruh kompensasi terhadap kinerja karyawan.

\section{METODE PENELITIAN}

Metode analisis yang dipergunakan dalam penelitian ini adalah Uji kelayakan data, uji hipotesis, dan uji variabel moderasi dengan menggunakan alat bantu program SPSS versi 16.0. Populasi dan sempel penelitian ini adalah seluruh karyawan PT. Titian Abadi Lestari yaitu sebanyak 70 orang. Adapun metode analisis yang digunakan yaitu: 1). Uji Validitas. Bertujuan mengukur sah atau valid tidaknya suatu kuesioner. Pertanyaan dikatakan valid apabila $r$ hitung > $r$ tabel; 2). Uji Reliabilitas. Diguakan Untuk mengukur indikator kuesioner dari variabel atau konstruk. kuesioner dikatakan reliabel/handal jika jawaban setiap pertanyaan konsisten/stabil dari waktu ke waktu. Suatu konstruk atau variabel dinyatakan reliabel jika nilai cronbach $\alpha>0.60 ; 3$ ); 4). Uji t (Secara Parsial). Untuk membuktikan pengaruh yang signifikan antara variabel independen terhadap variabel dependen, dimana apabila nilai t hitung $>\mathrm{t}$ tabel menunjukkan diterimanya hipotesis yang diajukan; 5). Uji F (Secara Simultan). Menunjukkan apakah variabel bebas yang ada mempunyai pengaruh secara bersama-sama terhadap variabel terkait apabila $\mathrm{r}$ hitung $<\mathrm{r}$ tabel; dan 6). Uji Moderasi. Apabila variabel hasil perkalian antara variabel bebas dengan variabel yang dihipotesiskan sebagai variabel moderasi signifikan, maka dapat disimpulkan bahwa variabel yang dihipotesiskan sebagai variabel moderasi benar-benar memoderasi hubungan antara variabel bebas dengan variabel tergantung.

\section{HASIL PENELITIAN}

Proses pengelolaan data dimulai dengan uji kelayakan data, uji hipotesis dan uji variabel moderasi. Berikut penjelasan hasil penelitian: 


\section{ISSN 1411-0830}

Tabel 1

Hasil Uji t

\section{Coefficients ${ }^{\mathrm{s}}$}

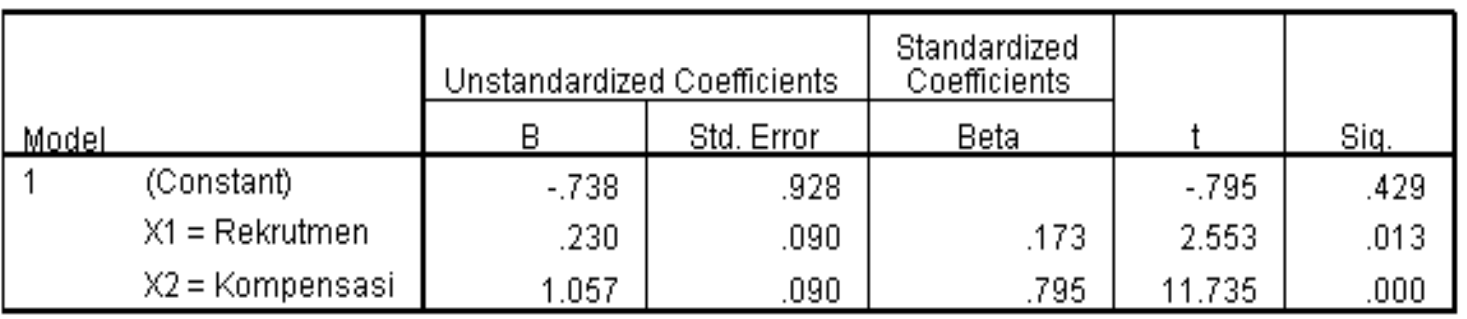

a. Dependent Variable: $Y=$ Kinerja Karyawan

Tabel 2

Hasil Uji F

ANOVA ${ }^{\text {b }}$

\begin{tabular}{|c|c|c|c|c|c|c|}
\hline & & $\begin{array}{c}\text { Sum of } \\
\text { Squares }\end{array}$ & $\mathrm{df}$ & Mean Square & $\mathrm{F}$ & Sig. \\
\hline \multirow[t]{3}{*}{1} & Regression & 1079.307 & 2 & \multirow{3}{*}{$\begin{array}{r}539.653 \\
2.407\end{array}$} & \multirow[t]{3}{*}{224.188} & \multirow[t]{3}{*}{$.000^{=}$} \\
\hline & Residual & 161.279 & 67 & & & \\
\hline & Total & 1240.586 & 69 & & & \\
\hline
\end{tabular}

a. Predictors: (Constant), $X 2=$ Kompensasi, $X 1=$ Rekrutmen

b. Dependent Variable: $Y=$ Kinerja Karyawan

Berdasarkan Tabel 1, dapat diketahui bahwa nilai $\mathrm{t}$ hitung untuk $\mathrm{X}_{1}$, yaitu sebesar 2,553 > t tabel 1,99547 dengan nilai signifikan 0,013. Serta nilai $t$ hitung untuk $X_{2}$, yaitu sebesar $11,735>\mathrm{t}$ tabel 1,99547 dengan nilai signifikan 0,000. Sedangkan berdasarkan Tabel
2, dapat diketahui bahwa $\mathrm{F}$ hitung sebesar $224,188>\mathrm{F}$ tabel sebesar 3,13 dengan nilai signifikan 0,000. Sehingga dapat disimpulkan bahwa rekrutmen dan kompensasi berpengaruh terhadap kinerja karyawan.

Tabel 3

Hasil Uji Moderasi $\mathrm{X}_{1}$ Tahap I Coefficients ${ }^{\mathrm{s}}$

\begin{tabular}{|c|c|c|c|c|c|c|}
\hline \multirow{2}{*}{\multicolumn{2}{|c|}{ Madel }} & \multicolumn{2}{|c|}{ Unstandardized Coefficients } & \multirow{2}{*}{$\begin{array}{c}\begin{array}{c}\text { Standardized } \\
\text { Coefficients }\end{array} \\
\text { Beta }\end{array}$} & \multirow[b]{2}{*}{$t$} & \multirow[b]{2}{*}{ Sig. } \\
\hline & & $\mathrm{B}$ & Std. Error & & & \\
\hline \multirow[t]{3}{*}{1} & (Constant) & .143 & .769 & & .186 & .853 \\
\hline & X1 = Rekrutmen & .201 & .076 & .151 & 2.633 & .010 \\
\hline & $Z=$ Pengawasan Kerja & 1.070 & .074 & .832 & 14.527 & .000 \\
\hline
\end{tabular}

a. Dependent Variable: $Y=$ Kinerja Karyawan

Tabel 4

Hasil Uji Moderasi dengan Interaksi $Z * \mathrm{X}_{1}$ Tahap II Coefficients

\begin{tabular}{|c|c|c|c|c|c|c|}
\hline \multirow{2}{*}{\multicolumn{2}{|c|}{ Madel }} & \multicolumn{2}{|c|}{ Unstandardized Coefficients } & \multirow{2}{*}{$\begin{array}{c}\begin{array}{c}\text { Standardized } \\
\text { Coefficients }\end{array} \\
\text { Beta } \\
\end{array}$} & \multirow[b]{2}{*}{$t$} & \multirow[b]{2}{*}{ Siq. } \\
\hline & & $\mathrm{B}$ & Std. Error & & & \\
\hline \multirow[t]{4}{*}{1} & (Constant) & -3.354 & 2.475 & & -1.355 & .180 \\
\hline & X1 = Rekrutmen & .489 & .208 & .368 & 2.346 & .022 \\
\hline & $Z=$ Pengawasan Kerja & 1.308 & .176 & 1.018 & 7.421 & .000 \\
\hline & Interaksi $Z * \times 1$ & -.019 & .013 & -.381 & -1.485 & .142 \\
\hline
\end{tabular}

a. Dependent Variable: $Y=$ Kinerja Karyawan 
Ari Soeti Yani dan Rinaldo, Pengaruh Rekrutmen Dan Kompensasi Terhadap Kinerja Karyawan...

Berdasarkan Tabel 3, disimpulkan bahwa pengaruh $\mathrm{Z}$ terhadap $\mathrm{Y}$ hasilnya adalah positif yang berarti bahwa moderasi dari pengawasan kerja memperkuat pengaruh rekrutmen terhadap kinerja dengan nilai signifikan 0,000. Sedangankan Tabel 4, dapat disimpulakn bahwa pengaruh interaksi $\mathrm{Z}^{*} \mathrm{X}_{1}$ terhadap Y hasilnya adalah negatif yang berarti bahwa moderasi dari pengawasan kerja memperlemah pengaruh kinerja dan tidak signifikan. Sehingga dapat dikatakan bahwa pengawasan kerja merupakan pure moderator, dikarenakan pengaruh $\mathrm{Z}$ terhadap $\mathrm{Y}$ salah satunya signifikan.

Tabel 5

Hasil Uji Moderasi X 2 Tahap I Coefficients $^{3}$

\begin{tabular}{|c|c|c|c|c|c|c|}
\hline \multirow{2}{*}{\multicolumn{2}{|c|}{ Madel }} & \multicolumn{2}{|c|}{ Unstandardized Coefficients } & \multirow{2}{*}{$\begin{array}{c}\begin{array}{c}\text { Standardized } \\
\text { Coefficients }\end{array} \\
\text { Beta } \\
\end{array}$} & \multirow[b]{2}{*}{$t$} & \multirow[b]{2}{*}{ Siq. } \\
\hline & & B & Std. Error & & & \\
\hline \multirow[t]{3}{*}{1} & (Constant) & -.084 & .724 & & -.116 & .908 \\
\hline & $X_{2}=$ Kompensasi & .476 & .124 & .358 & 3.834 & .000 \\
\hline & $Z=$ Pengawasan Kerja & .791 & .120 & .615 & 6.583 & .000 \\
\hline
\end{tabular}

a. Dependent Variable: $Y=$ Kinerja Karyawan

Tabel 6

Hasil Uji Moderasi dengan Interaksi $Z * X_{2}$ Tahap II Coefficients ${ }^{\mathrm{s}}$

\begin{tabular}{|c|c|c|c|c|c|c|}
\hline \multirow{2}{*}{\multicolumn{2}{|c|}{ Madel }} & \multicolumn{2}{|c|}{ Unstandardized Coefficients } & \multirow{2}{*}{$\begin{array}{c}\begin{array}{c}\text { Standardized } \\
\text { Coefficients }\end{array} \\
\text { Beta }\end{array}$} & \multirow[b]{2}{*}{$t$} & \multirow[b]{2}{*}{ Siq. } \\
\hline & & $\mathrm{B}$ & Std. Error & & & \\
\hline \multirow[t]{4}{*}{1} & (Constant) & -.439 & 1.876 & & -.234 & .816 \\
\hline & $\times 2=$ Kompensasi & .499 & .167 & .375 & 2.983 & .004 \\
\hline & $Z=$ Pengawasan Kerja & .827 & .215 & .643 & 3.856 & .000 \\
\hline & Interaksi $Z^{*} \times 2$ & -.002 & .011 & -.045 & -.205 & .838 \\
\hline
\end{tabular}

a. Dependent Variable: $Y=$ Kinerja Karyawan

Berdasarkan Tabel 5, disimpulkan bahwa pengaruh $\mathrm{Z}$ terhadap $\mathrm{Y}$ hasilnya adalah positif yang berarti bahwa moderasi dari pengawasan kerja memperkuat pengaruh kompensasi terhadap kinerja dengan nilai signifikan 0,000. Sedangkan Tabel 6, dapat disimpulakn bahwa pengaruh interaksi $Z * X_{2}$ terhadap $\mathrm{Y}$ hasilnya adalah negatif yang berarti bahwa moderasi dari pengawasan kerja memperlemah pengaruh kinerja dan tidak signifikan. Sehingga dapat dikatakan bahwa pengawasan kerja merupakan pure moderator, dikarenakan pengaruh $\mathrm{Z}$ terhadap $\mathrm{Y}$ salah satunya signifikan.

\section{PEMBAHASAN}

Dari uraian hasil penelitian di atas dapat dijelaskan bahwa:

Hipotesis $\mathrm{H}_{1}$ diterima, karena hasil penelitian menyatakan bahwa rekrutmen berpengaruh positif dan signifikan terhadap kinerja. Hal ini didukung dari hasil hasil penelitian Hidayat (2012) yang menyatakan bahwa rekrutmen berpengaruh sebesar 59,9\% terhadap kinerja karyawan. Dengan menunjukkan bahwa hampir $60 \%$ kinerja karyawan dapat dipengaruhi dari proses awal pencalonan karyawan. Sehingga semakin efisien pelaksanaan proses rekrutmen, maka semakin baik calon karyawan yang akan didapat perusahaan dan berdampak positif bagi peningkatan kinerja.

Hipotesis $\mathrm{H}_{2}$ diterima, karena hasil penelitian menyatakan bahwa kompensasi berpengaruh positif dan signifikan terhadap kinerja. Hal ini didukung dari hasil penelitian Ernawati (2013), menyatakan bahwa kompensasi mempunyai pengaruh positif dan signifikan terhadap sebesar 55, $8 \%$ yang artinya sekitar $56 \%$ kinerja karyawan dipengaruhi oleh kompensasi. Pemberian kompensasi membuat 
karyawan merasa lebih diperhatikan oleh perusahaan. Apabila karyawan merasa diperhatikan umumnya karyawan akan berusaha untuk berbuat yang terbaik bagi perusahaan, sehingga mendorong peningkatan kinerja dan tujuan perusahaan pun akan tercapai.

Hipotesis $\mathrm{H}_{3}$ diterima, karena hasil penelitian menyatakan bahwa rekrutmen dan kompensasi secara bersama - sama berpengaruh signifikan terhadap kinerja karyawan. Hal ini didukung dari hasil penelitian Sutrisno (2011), menyatakan bahwa rekrutmen dan kompensasi berkontribusi secara signifikan terhadap kinerja dengan tingkat persentasi sebesar 97,2 \% dan $2,8 \%$ dipengaruhi oleh variabel-variabel lainnya diluar variabel rekrutmen dan kompensasi.

Hipotesis $\mathrm{H}_{4}$ diterima, karena hasil penelitian menyatakan bahwa pengawasan kerja merupakan pure moderator atas pengaruh rekrutmen terhadap kinerja. Hal ini didukung dari hasil penelitian Suseno (2013), menyatakan bahwa pengawasan mempunyai pengaruh positif dan signifikan terhadap kinerja pegawai dengan nilai $\mathrm{R}^{2}$ sebesar 0,636 atau $63,6 \%$.

Hipotesis $\mathrm{H}_{5}$ diterima, karena hasil penelitian menyatakan bahwa pengawasan kerja merupakan pure moderator atas pengaruh kompensasi terhadap kinerja. Hal ini didukung dari hasil penelitian Aprianita (2013), menyatakan bahwa pengawasan berpengaruh positif dan signifikan terhadap kinerja pegawai. Dimana semakin baik kegiatan pengawasan yang dilakukan oleh manajer/pimpinan, semakin terarah pula peningkatan kinerja karyawan setiap harinya. Serta semakin optimal kinerja yang dicapai, maka tercapai pula tujuan perusahaan.

\section{SIMPULAN DAN SARAN}

\section{Simpulan}

Hasil yang sudah dikemukakan pada penjelasan sebelumnya dapat ditarik kesimpulan dari hasil analisis tersebut, yaitu: 1) Hasil analisis menunjukkan bahwa variabel rekrutmen berpengaruh positif dan signifikan terhadap kinerja karyawan; 2) Adanya pengaruh positif dan signifikan antara variabel kompensasi terhadap kinerja karyawan; 3) Hasil analisis rekrutmen dan kompensasi secara bersama sama juga berpengaruh positif dan signifikan terhadap kinerja karyawan; 4) Hasil analisis pengawasan kerja sebagai variabel moderating memperlemah pengaruh rekrutmen terhadap kinerja karyawan. Sehingga variabel pengawasan menjadi variabel pure moderating. Hal ini dikarenakan hasil pengaruh dari $\mathrm{Z}$ terhadap $Y$ pada output pertama dan pengaruh interaksi $Z * X_{1}$ pada output kedua, salah satunya signifikan; 5) Hasil analisis pengawasan kerja sebagai variabel moderating memperlemah pengaruh kompensasi terhadap kinerja karyawan, sehingga variabel pengawasan menjadi variabel pure moderating. Hal ini dikarenakan hasil pengaruh dari $\mathrm{Z}$ terhadap $\mathrm{Y}$ pada output pertama dan pengaruh interaksi $\mathrm{Z}^{*} \mathrm{X}_{2}$ pada output kedua, salah satunya signifikan.

\section{Saran}

Berdasarkan kesimpulan di atas saran yang dapat penulis berikan sebagai bahan masukan pihak perusahaan dalam upaya meningkatkan kinerja karyawan yaitu: 1) Menghimbau para karyawan agar lebih cekatan dan sigap dalam menjalankan pekerjaan; 2) Perusahaan hendaknya lebih selektif dalam memberikan kesempatan calon karyawan baru; 3) Lebih memerhatikan kebutuhan maupun fasilitas yang diberikan

Hendaknya pemimpin secara rutin atau berkala melakukan musyawarah apabila ada perubahan sistem dalam bekerja, agar tidak terjadi kesalahpahaman atau kesenjangan dalam bekerja.

\section{DAFTAR REFERENSI}

Ernawati, 2013, Analisis Pengaruh Kompensasi dan Kepemimpinan Terhadap Kinerja Karyawan (Studi Pada PT Njonja Meneer Semarang).

Online. Eprints.undip.ac.id/40083/ 
Ari Soeti Yani dan Rinaldo, Pengaruh Rekrutmen Dan Kompensasi Terhadap Kinerja Karyawan...

Harahap. 2001. Sistem Pengawasan Manajemen. Jakarta: Penerbit Quantum.

Handoko, 2003, Manajemen Personalia dan Sumber Daya Manusia. Yogyakarta: BPFE

Hasibuan. 2006. Manajemen Dasar, Pengertian, dan Masalah. Edisi Revisi. Bumi Aksara. Jakarta.

-------. 2009. Manajemen Sumber Daya Manusia. Edisi Revisi. Cetakan ketujuh. Bumi Aksara. Jakarta.

Hidayat.2012. Pengaruh Prosedur Rekrutmen dan Kualitas Sumber Daya Manusia Terhadap Kinerja Karyawan Di CV. Moza Tour \& Travel Tengahtani Kab. Cirebon. Online. Web.iaincirebon.ac.id

Mangkunegara. 2000. Manajemen Sumber Daya Manusia Perusahaan. Bandung: PT Remaja Rosdakarya
Mathis. L. Robert dan Jackson H. John. 2006. Manajemen Sumber Daya Manusia. Edisi Kesepuluh. Jakarta: Salemba Empat.

Sedarmayanti, 2001, Sumber Daya Manusia dan Produktivitas Kerja. Bandung: Mandar Maju.

Suseno, 2013, Pengaruh Pengawasan Terhadap Kinerja Pegawai Inspektorat Kabupaten Jember.

Online. http://repository.unej.ac.id/bitstream/handl e/123456789/7025/selvy\%2520Suseno\%2 $\underline{520-\% 2520050810291269 . p d f}$

Sutrisno, Wahyu Adi dan Syofruli Haroen, 2011, Pengaruh Rekrutmen, Pelatihan dan Kompensasi Terhadap Kinerja Karyawan PT. Saba Indomedika. Online. Library.binus.ac.id/Thesis/RelatedSubject/ 2011-2-00613-MN

Winardi, 2000, Manajer dan Manajemen. Bandung: Citra Aditya Bakti 